\title{
Correction to: Health coaching to improve self-management and quality of life for low income patients with chronic obstructive pulmonary disease (COPD): protocol for a randomized controlled trial
}

Beatrice Huang ${ }^{1 *}$, Rachel Willard-Grace ${ }^{1}$, Denise De Vore ${ }^{1}$, Jessica Wolf ${ }^{1}$, Chris Chirinos ${ }^{1}$, Stephanie Tsao ${ }^{2}$, Danielle Hessler ${ }^{1}$, George Su${ }^{3}$ and David H. Thom ${ }^{1}$

\section{Correction to: BMC Pulm Med}

https://doi.org/10.1186/s12890-017-0433-3

In the original article [1], the authors reference their intention to use the 'Morisky Medication Adherence Scale'. The scale is referenced in Table 1 and in the 'Measures' sub-section of the 'Methods' section.

This scale, however, was not used in the study.

The authors apologize for this error.

\section{Author details}

${ }^{1}$ Department of Family and Community Medicine, University of California San Francisco, San Francisco, CA, USA. ${ }^{2}$ San Francisco Department of Public Health, San Francisco, CA, USA. ${ }^{3}$ Department of Medicine: Pulmonology, Critical Care, Allergy and Sleep Medicine Program, University of California San Francisco, San Francisco, CA, USA.

Published online: 21 May 2019

\section{Reference}

1. Huang, et al. Health coaching to improve self-management and quality of life for low income patients with chronic obstructive pulmonary disease (COPD): protocol for a randomized controlled trial. BMC Pulm Med. 2017;17:90. https://doi.org/10.1186/s12890-017-0433-3.

\footnotetext{
*Correspondence: beatrice.huang@ucsf.edu

1 Department of Family and Community Medicine, University of California San Francisco, San Francisco, CA, USA

Full list of author information is available at the end of the article
} 